\title{
Synthesis, Characterization and Thermal Behavior of Poly(Vinyl) Chloride Reinforced by Folic Acid- modified Titanium Dioxide
}

Yiheng LU ( $\nabla$ yhlu@aust.edu.cn )

Anhui University of Science and Technology https://orcid.org/0000-0003-1958-2656

Yi-heng Lu

Universite de Paris Sud

Zong-li Chen

Universite de Paris Sud

Yu-wei Lu

Universite de Paris Sud

\section{Research Article}

Keywords: Polyvinyl chloride, folic acid-modified titanium dioxide, reinforcing agent, thermal behavior

Posted Date: May 5th, 2021

DOI: https://doi.org/10.21203/rs.3.rs-482575/v1

License: (9) This work is licensed under a Creative Commons Attribution 4.0 International License. Read Full License 


\section{Abstract}

To improve the environmental friendliness of polyvinyl chloride (PVC) and inhibit the agglomeration of nanotitanium dioxide, a PVC composite film reinforced by folic acid-modified titanium dioxide was synthesized and characterized using X-ray powder diffraction, thermogravimetric analysis, X-ray photoelectron spectroscopy and thermogravimetric analysis coupled with Fourier transform infrared spectroscopy. The average grain size of the folic acid-modified titanium dioxide particles decreased by $1.3 \mathrm{~nm}$, indicating that the cohesiveness of nanoparticles decreased. The induction period of hydrogen chloride release for PVC pyrolysis at $195^{\circ} \mathrm{C}$ was much higher than that of the control sample. After reinforcement with modified $\mathrm{TiO}_{2}$, the lowest temperature for $1.0 \%$ thermal decomposition of $\mathrm{PVC}$ was $230.0^{\circ} \mathrm{C}$, which is higher than the temperatures of the control sample. During the first decomposition stage, the peak temperature was $309.5^{\circ} \mathrm{C}$, and the degradation progressed to the high-temperature zone. The decomposition rate at this peak temperature is $39.6 \%$ lower than that of the control sample. Energy spectrum analysis shows that after adding modified $\mathrm{TiO}_{2}$, the stability of the PVC improved due to an increased number of surface oxygen atoms and a lower number of surface chlorine atoms, as well as the formation of intermolecular hydrogen bonds. Infrared spectroscopic analysis shows that after modification, the vibration peak intensities of ester groups 1264,1736 and $1106 \mathrm{~cm}^{-1}$ from the plasticizer decreased significantly. The enhanced PVC film suppressed the release of $\mathrm{CO}_{2}$, and the strongest vibration peak at $1264 \mathrm{~cm}^{-1}$ was $17.2 \%$ lower than that of the blank sample, indicating that the decomposition of plasticizer was inhibited by additives.

\section{Introduction}

As a thermoplastic polymer material, polyvinyl chloride (PVC) is widely used in building materials, packaging, electrical cables, and medical applications because of its low price, ease of processing, corrosion resistance, and flame resistance. However, PVC has the disadvantages of poor thermal stability and easy release of corrosive hydrogen chloride gas during molding and processing, resulting in performance degradation [1]. Commonly used stabilizers, co-stabilizers and auxiliary agents include hydrogen chloride traps or barriers that cut off the transmission of chlorine free radicals, such as calcium/zinc metal soaps, organotin, organic compounds (such as polyhydroxy compounds), rare earths, nanometal oxide particles and lead salts [2-6]. With increasing pressure to protect the environment, there is an urgent need for new composite stabilizers that are efficient, nontoxic, environmentally degradable or recyclable.

$\mathrm{PVC} / \mathrm{TiO}_{2}$ organic/inorganic nanocomposites are new materials that have attracted attention in recent decades. They combine inorganic nanoparticles in a polymer matrix and, in general, they can greatly improve mechanical and optical properties [7-11]. They are nontoxic, stable and resistant to ultraviolet radiation [12-14]. As a photocatalyst, nano $\mathrm{TiO}_{2}(\mathrm{NT})$ particles can effectively degrade a variety of pollutants and avoid the formation of highly toxic substances, such as dioxins [15-19]. However, NT particles have a large specific surface area and high surface energy, so they readily agglomerate and are 
difficult to disperse in a polymer. NT particles are inorganic metal oxide particles with strong polarity and a large number of hydroxyl groups on their surface, which are incompatible with PVC polymers because they are repelled. Therefore, there is an urgent need to solve the high surface energy, high hydrophilicity and repellency of NT with PVC.

Folic acid (FA) contains polar and nonpolar groups and is one of the candidate ligands. It is a pure natural vitamin that is safe and nontoxic. It contains multiple amino and carboxyl groups and shows weak acidity. As a ligand, it can form complexes with metals. The NT surface contains $\mathrm{OH}$, which can combine with the carboxyl and amino groups on the FA macromolecular structure to form electrostatic attraction, remove hydroxyl groups from the NT surface, reduce hydrophilicity and improve hydrophobicity. In this way, the compatibility and affinity of FA/NT with PVC can be increased.

To date, there are many reports of PVC composites that contain titanium dioxide, have photocatalytic antibacterial and mechanical properties, and are involved in photocatalytic degradation [20-31], but the heat resistance of PVC composites has not been improved. Therefore, the heat resistance of modified NTreinforced PVC composites is a long-term issue that needs to be solved. In this work, an FA surface modification NT complex-reinforced PVC composite film was synthesized to improve the dispersion of NT, reduce cohesion, increase compatibility with the PVC substrate and increase environmental friendliness. The hydrogen chloride release rate of the film during thermal degradation was measured, the films were characterized by XRD, FTIR and XPS, and the effect of FA/NT on the thermal stability and stability mechanism of the films was investigated. This study has never been reported in the literature. In addition, possible synergistic effects and the thermal behavior of FA/NT, CeSt ${ }_{3}$ and OT composites used on PVC substrates were also investigated. This study is beneficial to the development of a new type of environmentally friendly PVC/FA/NT composite film.

\section{Experimental Part}

\subsection{Materials}

Ordinary commercial PVC (S-65, degree of polymerization, 1000-1100) was obtained from Formosa Plastics Industry (Ningbo) Co., Ltd. (China). The plasticizer dioctyl terephthalate (DOTP) was analytically pure and supplied by Bluesail Group Co., Ltd. (Zibo,China). Methyl tin mercaptan (OT) was supplied by Jianhua Dongxu Chemical Co., Ltd. (Quzhou, China). CAS: 57583-35-4, structural formula (I) contains $75 \%$ and (II) $25 \%$. Cerium stearate (CeSt3), m.p. $105^{\circ} \mathrm{C}$, cerium content $11.0 \%$, $\left[\mathrm{C}_{17} \mathrm{H}_{35} \mathrm{COO}^{-}\right]_{3} \cdot \mathrm{Ce}^{+3}$ was an industrial qualified product and provided by Zibo Luchuan Rubber \& Plastic Co., Ltd. Folic acid, analytically pure, was supplied by Aladdin Biochemical Technology Co., Ltd. (Shanghai, China). Nanotitanium dioxide (NT), anatase type, $20 \mathrm{~nm}$, was supplied by Evonik Degussa AG. The structural formula of some raw materials is as follows: 


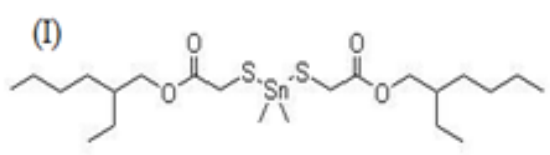

(II)

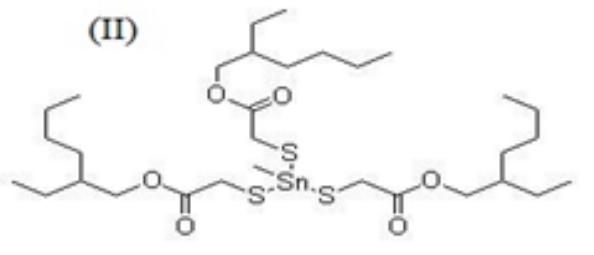

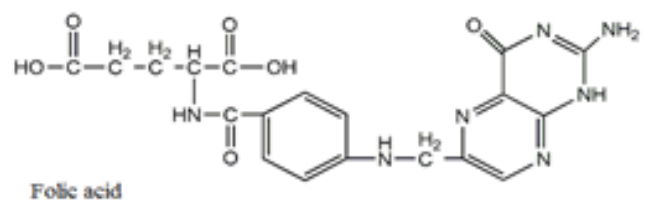

\subsection{Characterization}

Powder X-ray diffraction (XRD) patterns were recorded with a Rigaku Smart Lab SE diffractometer using a CuKa source $(\mathrm{I}=0.154060 \mathrm{~nm})$ at $40 \mathrm{~mA}$ and $40 \mathrm{kV}$.

Fourier transform infrared spectroscopy was conducted on a Thermo Fisher Scientific Nicolet iS 50 spectrophotometer using $\mathrm{KBr}$ pellets (sample/ $\mathrm{KBr}=1 / 100$ ), $\mathrm{PVC}$ film of $1.0 \times 1.0 \mathrm{~cm}$ for direct analysis, and a wavelength interval from $4000-500 \mathrm{~cm}^{-1}$ at a resolution of $4 \mathrm{~cm}^{-1}$.

Thermogravimetry (TG) curves were recorded in flowing nitrogen with a heating rate of $10^{\circ} \mathrm{C} \mathrm{min} \mathrm{m}^{-1}$ on a Perkin-Elmer Pyris 1 thermal analyzer. The temperature range was $25-700^{\circ} \mathrm{C}$, the flow rate of carrier gas was $100 \mathrm{ml} \mathrm{min}^{-1}$, and an alumina crucible was used.

The conductivity measurements used an SX713 conductivity meter to automatically display and record the results.

The surface structural changes of the PVC samples were characterized by an X-ray photoelectron spectrometer (XPS), model: Thermo Scientific ESCALAB 250Xi. An incident X-ray beam from the Al target (with an accelerating potential of $10 \mathrm{keV}$ and a current of $4 \mathrm{~mA}$ ) was focused on the surface of the sample with a $90^{\circ}$ electron take-off angle.

TG-FTIR: The pyrolysis behavior of PVC was analyzed by using a thermogravimetric analyzer (TGA, Perkin Elmer 8000)-Fourier transform infrared spectrometer (FTIR, Frontier). To reduce the heat transfer limitations, approximately $5.0 \pm 0.1 \mathrm{mg}$ of sample was added to the platinum crucible of the TGA and heated from room temperature to $700^{\circ} \mathrm{C}$ at a heating rate of $10^{\circ} \mathrm{C} \mathrm{min}{ }^{-1}$ under high purity $\mathrm{N}_{2}(99.999 \%)$ at a flow rate of $100 \mathrm{mLmin}^{-1}$. The gas emitted during pyrolysis was transported from the TGA to the FTIR spectrometer through a capillary bundle while the temperature was maintained at $200^{\circ} \mathrm{C}$. FTIR data were recorded in the range of $4000-500 \mathrm{~cm}^{-1}$ at a resolution of $4 \mathrm{~cm}^{-1}$.

\subsection{Determination of hydrogen chloride concentration}

The concentration of the aqueous solution of hydrogen chloride released during PVC pyrolysis was determined by conductivity conversion. The corresponding relationship between the concentration of $[\mathrm{HCl}]$ in the absorbing solution and the conductivity value, that is, the calculation of $[\mathrm{HCl}]$, can be expressed as (1) [32]: 
$[\mathrm{HCl}]_{\mathrm{t}}=\left[0.501 \mathrm{~V}_{\mathrm{t}}+0.01\right] \times 10^{-5} \mathrm{~mol} \mathrm{~L}^{-1}$

where $[\mathrm{HCl}]_{t}$ is the molar concentration of the

$\mathrm{HCl}$ solution at time $\mathrm{t}, \mathrm{V}_{\mathrm{t}}$ is the difference between the conductivity of the $\mathrm{HCl}$ solution at time $\mathrm{t}$ and the conductivity of deionized water, and 0.01 is the correction value that takes into account the presence of $\mathrm{CO}_{3}{ }^{2-}$ ions dissolved in water [32]; additional information on the conductivity measurement is supplied in the Supporting Information.

\subsection{Synthesis of the FAVNT}

The mass fraction of FA in the FA/NT composite was $5 \%$, and the required amounts of FA powder and NT were each weighed, dissolved in deionized water at $25^{\circ} \mathrm{C}$, and ultrasonicated for $15 \mathrm{~min}$. Each was then poured into the same container, mixed, and stirred. Then, ultrasonication was conducted for $30 \mathrm{~min}$ at $25^{\circ} \mathrm{C}$, evaporative dehydration was performed, and the samples were dried at $105^{\circ} \mathrm{C}$ to obtain the FA/NT particles.

\subsection{Preparation of PVC film}

The plasticizer (DOTP), thermal stabilizer (OT), co-stabilizer $\left(\mathrm{CeSt}_{3}\right)$, and reinforcing agent (FA (5\%)/NT) were weighed in proportion, combined at $80^{\circ} \mathrm{C}$ and ultrasonicated for $30 \mathrm{~min}$ to fully mix the materials and form a uniform viscous liquid. The viscous liquid was added to the PVC resin and mixed at 170$175^{\circ} \mathrm{C}$ at a speed of $40 \mathrm{r} \cdot \mathrm{min}^{-1}$. When the torque increased rapidly and then decreased, after mixing for 5 min, the PVC discharge was removed, and a flat vulcanizing machine was used at $100^{\circ} \mathrm{C}$ to compress it to a thickness of $1.0 \mathrm{~mm}$ to obtain a PVC sheet, as shown in Table 1.

Table 1 Composition of PVC film

\begin{tabular}{|llllll|}
\hline Sample & PVC resin & DOTP & OT & CeSt $_{3}$ & FA/NT \\
\cline { 2 - 6 } & \multicolumn{5}{c|}{$/$ phrs } \\
\hline S0 & 100 & 50 & & & \\
\hline S1 & 100 & 50 & 1.0 & & \\
\hline C-1 & 100 & 50 & 0.5 & 5.0 & 1.0 \\
\hline C-2 & 100 & 50 & 0.5 & 5.0 & 3.0 \\
\hline C-3 & 100 & 50 & 0.5 & 5.0 & 5.0 \\
\hline
\end{tabular}

(Note: The content of FA in FA/NT was $5 \mathrm{wt} \%, \mathrm{~S} 0$ is the blank sample, and S1 is the control sample) 


\section{Results And Discussion}

\subsection{Removal of hydrogen chloride by thermal decomposition of different films}

Fig. 1 shows the change in the concentration of aqueous hydrogen chloride solution released by thermal degradation of different PVC films over time. The stability of PVC film S1 with 1 phr OT was higher than that of SO without any additives, the thermal degradation of the PVC/FA/NT film and release of hydrogen chloride was obviously inhibited, and the thermal stability of C-1 was the best.

Table 2 Induction period of different PVCs that released hydrogen chloride

\begin{tabular}{|lll|}
\hline Sample & $\tau_{\mathrm{i}} / \min$ & $\tau_{\mathrm{m}} / \min$ \\
\hline S0 & 5 & 27 \\
\hline S1 & 28 & 49 \\
\hline C-1 & 70 & 138 \\
\hline C-2 & 56 & 119 \\
\hline C-3 & 59 & $128^{*}$ \\
\hline
\end{tabular}

(Note $\triangle \tau_{\mathrm{i}}$-Induction period; $\tau_{\mathrm{m}}$ - maximum value, that is $[\mathrm{HCl}]$

reaches $50 \times 10^{-5} \mathrm{~mol} \mathrm{~L}^{-1}, 41 \mathrm{~mol} \mathrm{~L}^{-1}$ )

Table 2 shows the induction period of different PVC films that released hydrogen chloride during thermal degradation. The induction period of $\mathrm{C}-1$ is $70 \mathrm{~min}$, which is the longest, and the induction periods of $\mathrm{C}-3$, C-2, S1 and S0 are 59, 56, 28 and 5 min, respectively. This trend shows that the FA/NT, CeSt 3 and OT strongly inhibited the release of hydrogen chloride from the PVC film or strongly interacted with the hydrogen chloride. The test results show that with the introduction of 1-3 phr FA/NT and $5 \mathrm{phr} \mathrm{CeSt}_{3}$, the stabilizing effect is far greater than with $0.5 \mathrm{phr}$ OT. OT enhances the ability of the other chemical agents to react with hydrogen chloride in the PVC. When the OT was partially replaced, the FA/NT and $\mathrm{CeSt}_{3}$ complex had a better synergistic effect on the OT; this effect was especially obvious when 1 phr FA/NT was added.

\subsection{Fourier transform reflectance infrared spectroscopy analysis of different films}

Fig. 2 shows the FT-IR spectra of different PVC films in the wavenumber range from $525-715 \mathrm{~cm}^{-1}$, in which the vibration peak near $608 \mathrm{~cm}^{-1}$ was attributed to characteristic groups of the C-Cl bond [33-35]. The width of the vibration peak from the $\mathrm{C}-\mathrm{Cl}$ bond on the surface of the PVC film after FA/NT modification was slightly larger than that of the control sample and the blank sample. The peak widths from large to small were $\mathrm{C}-3>\mathrm{C}-2>\mathrm{S} 1>\mathrm{C}-1>\mathrm{S} 0$, where the peak widths for $\mathrm{C}-3, \mathrm{C}-2$ and $\mathrm{S} 1$ were $7 \mathrm{~cm}^{-1}$ 
larger than those for $\mathrm{C}-1$ and S0. The differences in the vibration peaks in the wavenumbers from 715$4000 \mathrm{~cm}^{-1}$ before and after the modification were small. The reason may be that the surface coating and content of FA/NT only ranged from $0.64-3.12 \%$.

\subsection{X-ray diffraction analysis of different films}

Fig. 3 shows the XRD profiles of different PVC films. It can be seen from the figure that S0 and S1 had almost no characteristic diffraction peaks, and no crystalline particles existed in the samples. C-1, C-2 and $\mathrm{C}-3$ generated obvious diffraction peaks in the $2 \theta$ range from $15.0 \sim 35.0^{\circ}$, indicating that FA/NT and PVC had a strong interaction, and they were located on the surface of PVC [6](see Figure S2). The diffraction peak intensity from large to small was $C-1>C-2>C-3$, indicating that the crystallinity of the sample decreased with increasing FA/NT complex content. This trend is close to the trend from the hydrogen chloride release experiment. As the content of FA/NT increased, the stability of PVC during thermal degradation decreased.

\subsection{X-ray photoelectron spectroscopic analysis of different films}

XPS spectra of films C-1, C-2 and C-3 are shown in Fig.4. Unlike film C-1, new Sn peaks are observed at C2 and C-3, which are $486.3 \mathrm{eV}$ and $495.7 \mathrm{eV}$, respectively.

The high resolution spectra of the $C$ 1s regions are depicted in Fig.5(a-c). In the $C$ 1s spectrum of the C-1, C-2 and C-3 films, the three components 1,2 and 3 in the $C$ Is spectra corresponded exactly to three types of carbon bonds: $\mathrm{C}-\mathrm{C}(284.76 \mathrm{eV}), \mathrm{C}-\mathrm{O}$ and $\mathrm{C}-\mathrm{N}(286.39 \mathrm{eV})$ and amide $\mathrm{C}=\mathrm{O}(289.07 \mathrm{eV})$.

As displayed in Fig.6 (a), two different types of oxygen components, $\mathrm{O}=\mathrm{C}(532.03 \mathrm{eV})$ and $\mathrm{O}-\mathrm{C}$ (533.52 $\mathrm{eV}$ ), were present in the $01 \mathrm{~s}$ spectrum of the $\mathrm{C}-1$ film. In the $01 \mathrm{~s}$ spectrum of high-resolution scans of the $\mathrm{O}$ 1s region of Fig.(b) $\mathrm{C}-2$ and $(\mathrm{c}) \mathrm{C}-3$, although oxygen groups $(\mathrm{O}=\mathrm{C})$ still remained, the peak intensities of $\mathrm{C}-1$ groups $(\mathrm{O}=\mathrm{C})$ decreased obviously. With the increase in the amount of FA/NT added, a new peak was generated near $534.35 \mathrm{eV}$, indicating that the carbonyl group was involved, and the carbonyl group was derived from DOTP and FA.

As depicted in Fig.7(c), the high-resolution $\mathrm{Cl} 2 \mathrm{p}$ spectrum of the $\mathrm{C}-3$ film showed that there were two different chlorine components: 200.10 and 201.70 eV. In contrast, in the spectra shown in Fig.7 (a) and (b), new peaks centered at 198.35 and $198.35 \mathrm{eV}$ appeared and were assigned to hydrogen bonds. The former peak corresponds to a weaker C-1 hydrogen bond.

Table 3 XPS element distributions 


\begin{tabular}{|llllll|}
\hline Sample & $\mathrm{C} 1 \mathrm{~s}(\%)$ & $\mathrm{O} 1 \mathrm{~s}(\%)$ & $\mathrm{Cl} 2 \mathrm{p}(\%)$ & $\mathrm{O} / \mathrm{C}$ & $\mathrm{Cl} / \mathrm{C}$ \\
\hline $\mathrm{C}-1$ & 76.14 & 19.38 & 4.48 & 0.25 & 0.06 \\
\hline $\mathrm{C}-2$ & 78.10 & 15.96 & 5.94 & 0.20 & 0.08 \\
\hline $\mathrm{C}-3$ & 77.37 & 14.93 & 7.70 & 0.19 & 0.10 \\
\hline
\end{tabular}

The XPS binding energy data for the composite films are shown in Table 3. There were many sources of $\mathrm{C} 1 \mathrm{~s}$ in the sample, which may be due to the increase in FA content in the FA/NT, resulting in the increase in $\mathrm{C}$ 1s content.

The content of 01 s in $\mathrm{C}-1, \mathrm{C}-2$ and $\mathrm{C}-3$ decreased in turn, and the $\mathrm{O} / \mathrm{C}$ ratio dropped from 0.25 to 0.19 . The main $01 \mathrm{~s}$ contribution came from DOTP, followed by contributions from OT and FA. This was due to $\mathrm{O}$ atoms, such as those in FA and DOTP, involved in hydrogen bond formation in the PVC system, resulting in an increase in the surface oxygen atom concentration.

The content of surface $\mathrm{Cl} 2 \mathrm{p}$ in $\mathrm{C}-1, \mathrm{C}-2$ and $\mathrm{C}-3$ increased in turn, and the $\mathrm{Cl} / \mathrm{C}$ ratio increased from 0.06 to 0.10 . The $\mathrm{Cl} 2 p$ signals mainly came from the PVC resin. This result indicates that with increasing FA/NT, the surface chlorine from C-2 and C-3 films that is not involved in the formation of hydrogen bonds increases. Therefore, the $1 \mathrm{phr}$ FA/NT complex produced a strong interaction with the PVC polar groups through hydrogen bonds, which was the reason for the improvement of its heat resistance.

\subsection{Thermogravimetric analysis}

Fig.8 shows the TG-DTG curves of the different PVC films. The carrier gas was N2, and the heating rate was $10^{\circ} \mathrm{C} \mathrm{min}-1$. It can be seen from the figure that the thermal degradation of the different PVCs underwent two stages, and the first and second stages of degradation occurred in the ranges of 201$385^{\circ} \mathrm{C}$ and $385-547^{\circ} \mathrm{C}$, respectively. During each decomposition stage, $\mathrm{C}-1$ was better than $\mathrm{S} 1$ and the other samples, as it withstood higher temperatures. During the first decomposition stage, when the conversion rate was $1 \%$, the initial decomposition temperature of $\mathrm{C}-1$ was $230.0^{\circ} \mathrm{C}$, while the initial decomposition temperatures of S0 and S1 were 175.1 and $210.8^{\circ} \mathrm{C}$, respectively. The temperature for $\mathrm{C}-1$ was significantly higher than those of S0 and S1.

Table 4 The decomposition temperatures of the PVC films at different conversion rates 


\begin{tabular}{|llllll|}
\hline $\mathrm{a}$ & $\mathrm{S} 0$ & $\mathrm{~S} 1$ & $\mathrm{C}-1$ & $\mathrm{C}-2$ & $\mathrm{C}-3$ \\
\cline { 2 - 6 }$/ \%$ & \multicolumn{5}{c|}{$/{ }^{\circ} \mathrm{C}$} \\
\hline 1 & 175.1 & 210.8 & 230.0 & 212.7 & 198.2 \\
\hline 5 & 244.1 & 250.5 & 260.0 & 248.6 & 251.3 \\
\hline 10 & 264.1 & 267.7 & 272.9 & 262.7 & 265.8 \\
\hline 80 & 432.1 & 435.7 & 447.7 & 451.0 & 446.6 \\
\hline 90 & 477.1 & 478.6 & 495.0 & 703.5 & 511.4 \\
\hline
\end{tabular}

Table 4 shows the decomposition temperatures of the PVC films for different conversion rates. When the conversion rate was $5 \%$, the thermal degradation temperatures of C-1, C-2, C-3, S1 and S0 were 271.8, $251.3,250.5,248.6$ and $244.1^{\circ} \mathrm{C}$, respectively, showing a decreasing trend. C-1 degraded at the highest temperature of $271.8^{\circ} \mathrm{C}$, and the shift to the high-temperature zone was the most obvious.

Table 5 The decomposition rates of the PVC film at different temperatures

\begin{tabular}{|llllll|}
\hline $\mathrm{T} /{ }^{\circ} \mathrm{C}$ & $\mathrm{S} 0$ & $\mathrm{~S} 1$ & $\mathrm{C}-1$ & $\mathrm{C}-2$ & $\mathrm{C}-3$ \\
\cline { 2 - 6 } & & \multicolumn{5}{c|}{$\% \mathrm{~min}^{-1}$} \\
\hline 200 & 0.619 & 0.168 & 0.120 & 0.209 & 0.155 \\
\hline 300 & 22.75 & 19.81 & 10.85 & 10.53 & 10.85 \\
400 & 0.736 & 0.603 & 0.400 & 0.379 & 0.384 \\
450 & 4.334 & 2.513 & 2.210 & 2.384 & 2.289 \\
\hline 500 & 1.714 & 0.602 & 0.630 & 0.585 & 0.586 \\
\hline 700 & 0.797 & 0.008 & 0.006 & 0.022 & 0.022 \\
\hline
\end{tabular}

Table 5 shows the decomposition rates of the PVC films at different temperatures. The decomposition rates of $\mathrm{C}-1, \mathrm{C}-2, \mathrm{C}-3, \mathrm{~S} 1$ and S0 during the first decomposition stage at $300^{\circ} \mathrm{C}$ were $12.55,10.53,10.85$, 19.81 and $22.75 \% \mathrm{~min}^{-1}$, respectively. The decomposition rate of PVC after modification decreased significantly compared with that of the control sample and the blank sample.

Table 6 Characteristic temperatures of different PVC films 


\begin{tabular}{|lllllll|}
\hline Sample & S0 & S1 & $\mathrm{C}-1$ & $\mathrm{C}-2$ & $\mathrm{C}-3$ & Stage \\
\hline $\mathrm{T}_{\mathrm{p}} /{ }^{\circ} \mathrm{C}$ & 308.1 & 302.2 & 309.5 & 304.2 & 308.5 & $1^{\text {st }}$ \\
\hline $\mathrm{da} / \mathrm{dt}\left(\% \mathrm{~min}^{-1}\right)$ & 29.40 & 20.26 & 14.51 & 10.91 & 12.47 & \\
\hline $\mathrm{T}_{\mathrm{p}} /{ }^{\circ} \mathrm{C}$ & 464.1 & 455.8 & 464.8 & 454.5 & 456.1 & $2^{\text {nd }}$ \\
\hline $\mathrm{da} / \mathrm{dt}\left(\% \mathrm{~min}^{-1}\right)$ & 5.55 & 2.57 & 2.67 & 2.59 & 2.61 & \\
\hline
\end{tabular}

Table 6 shows the characteristic temperatures of the different PVC films. It can be seen from the table that during the first decomposition stage, the peak temperatures of C-1, C-2, C-3, S1 and S0 were 309.5, $304.2,308.5,302.2$ and $308.1^{\circ} \mathrm{C}$, respectively, and the corresponding decomposition rates were 14.51 , $10.91,12.47,20.26$ and $29.40 \% \mathrm{~min}^{-1}$, respectively. The peak temperature for $\mathrm{C}-1$ was $309.5^{\circ} \mathrm{C}$, which was obviously in the high-temperature zone and was higher than that for S1 and S0. The decomposition rate of C-1 at the peak temperature was 39.6 and $102.6 \%$ lower than that of S1 and S0, respectively. During the second decomposition stage, the maximum decomposition rate of S0 was $5.55 \% / \mathrm{min}$, and the rest of the rates were similar and decreased to $2.5-2.7 \% / \mathrm{min}$.

\subsection{TG- FTIR analysis}

The gas phase 3D TG-FTIR spectra of C-1 and S0 sample pyrolysis are shown in Fig. 9, where the $\mathrm{x}$ coordinate is time/second, the $y$ coordinate is wavenumbers $/ \mathrm{cm}^{-1}$, and $\mathrm{z}$ is absorbance. Figure $6 \mathrm{a}$ is a TG-IR perspective of the $\mathrm{C}-1$ sample.There are four stronger infrared absorption peaks at $1621 \mathrm{~s}, 1626 \mathrm{~s}$, $1674 \mathrm{~s}$ and $1653 \mathrm{~s}$, with absorbance peak intensities of $0.2562,0.1604,0.1498$ and 0.1085 , respectively.

Fig.10 shows infrared spectra of released gas at different temperatures, wherein the black curve represents C-1 and the red curve represents S0. As shown in Fig.10 (a), a and b are the infrared spectra of the gas phase at $250^{\circ} \mathrm{C}$. A small amount of gas was released, but the difference was not significant. C and $\mathrm{d}$ are the vibration peaks at pyrolysis times of $1643 \mathrm{~s}\left(310.8^{\circ} \mathrm{C}\right)$ and $1624 \mathrm{~s}\left(307.7^{\circ} \mathrm{C}\right)$, respectively, which included the hydrogen chloride removal stage where $\mathrm{C}-1$ shifted to the high temperature zone.

The vibration peak near $1264 \mathrm{~cm}^{-1}$ is attributed to esters from DOTP in C-1. Its intensity is significantly lower than that of S0, and the peak intensity decreases by $17.3 \%$. The vibration peaks near 2950 and $2798 \mathrm{~cm}^{-1}$ are attributed to hydrogen chloride gas [36], the peaks near 1736, 1264, 1106 and $1024 \mathrm{~cm}^{-1}$ are attributed to the ester group $\mathrm{v}_{(\mathrm{COOR})}$ from the plasticizer DOTP [37], and $671 \mathrm{~cm}^{-1}$ is attributed to stretching of $\mathrm{v}_{(\mathrm{C}-\mathrm{Cl})}$ groups $[36,38]$. The peak strength of C-1 after modification decreases obviously compared with $\mathrm{S} 0$, which shows that the $\mathrm{C}-1$ heat resistance is enhanced.

The absorption peak from Fig. 10 (b) shows that upon heating from $350^{\circ} \mathrm{C}$ to $500^{\circ} \mathrm{C}$, the vibration peaks at $2600-3100 \mathrm{~cm}^{-1}$ disappeared first, and then a weaker hydrocarbon vibration peak was generated. The vibration peaks near 1736, 1264, 1106, 1024 and $671 \mathrm{~cm}^{-1}$ almost disappeared and became weaker, 
indicating that DOTP gasification products were minimal and that the removal of hydrogen chloride was almost complete. The conjugated polyenes started to polymerize. Here, infrared spectra e, $\mathrm{g}$ and $\mathrm{i}$ represent $\mathrm{C}-1 ; \mathrm{f}, \mathrm{h}$ and $\mathrm{j}$ represent $\mathrm{S} 0$.

As shown in Fig.10 (c), the second stage of PVC thermal degradation occurred at $600^{\circ} \mathrm{C}$, and the vibration peak of carbon dioxide occurred between $2318-2372 \mathrm{~cm}^{-1}$. During this stage, $\mathrm{SO}$ began to release $\mathrm{CO}_{2}$, while $\mathrm{C}-1$ inhibited $\mathrm{CO}_{2}$ overflow. At $700^{\circ} \mathrm{C}$, the peak height of the signal from the $\mathrm{CO}_{2}$ released from S0 further increased compared with that from $\mathrm{C}-1$, which also inhibited $\mathrm{CO}_{2}$ release and inhibited the degradation of the plasticizer DOTP, facilitating the recovery of DOTP. In the infrared spectra, $\mathrm{k}$ and $\mathrm{m}$ represent $\mathrm{C}-1$ and $\mathrm{I}$ and $\mathrm{n}$ represent $\mathrm{S} 0$. Therefore, after enhancement, the intensities of the vibration peaks at 1264, 1736, 1106 and $1024 \mathrm{~cm}^{-1}$ were due to a significant decrease in DOTP, which shows that the additive had a strong interaction with DOTP, which inhibits the thermal degradation of PVC and improves the thermal stability of the C-1 film.

Scheme 1 describes the possible interactions of the FA-modified NT-reinforced PVC composite film.

FA contains two carboxyl groups, one amino group and three secondary amino groups, which easily generate intramolecular and intermolecular van der Waals forces and $\mathrm{O}$ or $\mathrm{N}$ intermolecular hydrogen bonds when interacting with NT surface polyhydroxyl groups. The excess hydroxyl groups on the NT surface easily formed hydrogen bonds with $\mathrm{Cl}$ atoms in the PVC molecule, which inhibited the initiation of chlorine free radicals when the PVC was heated. However, as the addition of FA/NT increased from 3 to 5 phr, the compatibility with PVC decreased.

\section{Conclusion}

NT modified by FA was synthesized using ultrasonic radiation, and reinforced PVC polymer films were prepared to reduce the agglomeration of nanoparticles, enhance the compatibility with PVC, and improve the thermal properties. The results show that the FA/NT peak intensities from the composite diffraction peaks decreased; as the amount of modified NT increased from 3 to 5 phr, it became incompatible with PVC. The induction period of hydrogen chloride released from modified PVC at $195^{\circ} \mathrm{C}$ in a nitrogen atmosphere was much higher than that of the control and blank samples. The minimum temperature of $1.0 \%$ thermal decomposition of the composite film with $1 \mathrm{phr} F A / \mathrm{NT}$-reinforced PVC was $230.0^{\circ} \mathrm{C}$, which is much higher than the decomposition temperatures of $210.8^{\circ} \mathrm{C}$ and $175.1^{\circ} \mathrm{C}$ for the control sample and the blank sample, respectively. The peak temperature during the first decomposition stage was $309.5^{\circ} \mathrm{C}$, which brought the decomposition of the PVC into the high-temperature zone, and the decomposition rate at this peak temperature was 39.6 and $102.6 \%$ lower than those of the control sample and the blank sample, respectively. Energy spectrum analysis showed that after adding $1 \mathrm{phr} F A / N T$, the improved stability of the PVC composite film was due to an increased number of surface oxygen atoms, a lower number of surface chlorine atoms, and the formation of intermolecular hydrogen bonds. Compared with 
the blank sample, the enhanced PVC film suppressed the release of $\mathrm{CO}_{2}$, and the vibration peak intensities of ester groups 1264, 1736, 1106 and $1024 \mathrm{~cm}^{-1}$ came from a significant decrease in DOTP, indicating that the additive has a strong interaction with DOTP. The strongest vibration peak at $1264 \mathrm{~cm}^{-1}$ was reduced by $17.2 \%$ compared with that of the blank sample, indicating that the PVC film suppressed the decomposition of the plasticizer DOTP and improved the heat resistance.

\section{Declarations}

\section{Acknowledgments}

Financial support from the National Natural Science Foundation of China (grant number: 21775002) are gratefully acknowledged.

\section{References}

1. D. Braun, Poly (vinyl chloride) on the way from the 19 th century to the 21 st century. J Polym Sci Pol Chem

2. $42 ., 578(2004)$

3. M. Fu, D.G. Li, H. Liu, H.Q. Ai, Y.L. Zhang, L.P. Zhang, Synergistic effects of zinc-mannitol alkoxide with

4. calcium/zinc stearates, and with $\beta$-diketone on thermal stability of rigid poly (vinyl chloride). J Polym Res. 23, 1 (2016)

5. K. Chaochanchaikul, V. Rosarpitak, N. Sombatsompop, Structural and thermal stabilizations of PVC and wood/PVC composites by metal stearates and organotin. Bioresources. 6, 3115 (2011)

6. M.Y. Xue, Y.H. Lu, K. Li, B. Wang, Y.W. Lu, Thermal characterization and kinetic analysis of polyvinyl chloride containing $\mathrm{Sn}$ and Zn. J. Therm Anal Calorim. 139,1479(2020)

7. Z.G. Liu, J.W. Fan, J.M. Feng, M. Li, F.S. Feng, Study on the use of rare earth stabilizer as poly (vinyl chloride) stabilizer. J Vinyl Addit Technol 3, 1 (2020)

8. B. Wang, Y.H. Lu, Y.W. Lu, Organic tin, calcium-zinc and titanium composites as reinforcing agents and its effects on the thermal stability of polyvinyl chloride. J. Therm. Anal. Calorim. 142, 671 (2020)

9. K. Chrissafis, D.Bikiaris. Can nanoparticles really enhance thermal stability of polymers Part I: An overview on

10. thermal decomposition of addition polymers, Thermochim. Acta 523, 1 (2011)

11. K. Pielichowska, K. Nowicka, Analysis of nanomaterials and nanocomposites by thermo analytical methods

12. Thermochimica Acta. $675,140(2019)$

13. C.J. Yang, C.Q. Gong, T.Y. Peng, K.J. Deng, L. Zan, High photocatalytic degradation activity of the polyvinyl 
14. chloride (PVC, )-vitamin C (VC)-TiO2 nano-composite film. J. Hazard. Mater. 178, 152 (2010)

15. H. Rabiee, M.H.D.A. Farahani, V. Vatanpour, Preparation and characterization of emulsion poly (vinyl chloride)

16. (EPVC)/TiO, 2 nanocomposite ultrafiltration membrane. J Membrane Sci. 472, 185 (2014)

17. S. Xu, J. Xu, J.Zhang, Surface topography and cooling effects in poly(vinyl chloride) (PVC)/titanium dioxide $\left(\mathrm{TiO}_{2}\right)$ composites exposed to UV-irradiation. Iranian Polymer Journal. 27, 1011 (2018)

18. P. Sokhandani, A.A. Babaluo, M. Rezaei, M. Shahrezaei, R. Mehdizadeh, Nanocomposites of $\mathrm{PVC} / \mathrm{TiO} 2$ nanorods

19. surface tension, and mechanical properties before and after UV exposure. J. Appl. Polym. Sci. 129, 3265 (2013)

20. Y. Zhang, T.Y. Sun, D.S. Zhang, Z.F. Shi, X.P. Zhang, C. Li, L.L. Wang, J.J. Song, Q. Lin, Enhanced photo-degradability of PVC plastics film by codoping nano-graphite and TiO2. Polym Degrad Stabil. 181, 109332 (2020)

21. T.C. Yang, T. Noguchi, M. Isshiki, J.H. Wu, Effect of titanium dioxide particles on the surface morphology and the mechanical properties of PVC composites during QUV accelerated weathering. Polym Composite

22. 37., 3391(2016)

23. S.H. Kim, S.Y. Ahn, S.Y. Kwak, Suppression of dioxin emission in incineration of poly

24. (vinylchloride)(PVC, ) as hybridized with titanium dioxide (TiO2) nanoparticles. Applied Catalysis B: Environmental. 79, 296 (2008)

25. T. Katami, A. Yasuhara, T. Okuda, T. Shibamoto, Formation of PCDDs, PCDFs, and coplanar PCBs from polyvinyl chloride during combustion in an incinerator. Environ. Sci. Technol. 36, 1320 (2002)

26. M. Miyauchi, Y.J. Li, H. Shimizu, Enhanced degradation in nanocomposites of $\mathrm{TiO}_{2}$ and biodegradable polymer. Environ. Sci. Technol. 42, 4551 (2008)

27. J. Choi, O. Kim, S.Y. Kwak, Suppression of dioxin emission in co-incineration of poly (vinyl chloride) with $\mathrm{TiO}_{2}$-encapsulating polystyrene. Environ. Sci. Technol. 41, 5833(2007)

28. S. Horikoshi, N. Serpone, Y. Hisamatsu, H. Hidaka, Satoshihorikoshi, Nickserpone, Yoshiharuhisamatsu, Hisaohidaka. Photocatalyzed degradation of polymers in aqueous semiconductor suspensions. 3. photooxidation of a solid polymer: $\mathrm{TiO}_{2}$-blended poly (vinyl chloride) film. Environ. Sci. Technol. 32, 4010(1998)

29. S.M. Cho, W.O. Choi, Solid-phase photocatalytic degradation of $\mathrm{PVC}-\mathrm{TiO}_{2}$ polymer composites. Journal of Photochemistry and Photobiology A: Chemistry. 143, 221 (2001)

30. S.H. Kim, S.Y. Kwak, T. Suzuki, Photocatalytic degradation of flexible $\mathrm{PVC} / \mathrm{TiO}_{2}$ nanohybrid as an eco-friendly alternative to the current waste landfill and dioxin-emitting incineration of post-use PVC. Polymer. 47, 3005 (2006) 
31. W.H. Deng, S.B. Ning, Q.Y. Lin, H.L. Zhang, T.H. Zhou, H.X. Lin, J.L. Long, Q. Lin, X.X. Wang, I$\mathrm{TiO}_{2}$ /PVC film with highly photocatalytic antibacterial activity under visible light. Colloids and Surfaces B: Biointerfaces. 144, 196 (2016)

32. K. Chaochanchaikul, N. Sombatsompop, Stabilizations of molecular structures and mechanical properties of PVC and Wood/PVC composites by Tinuvin and $\mathrm{TiO}_{2}$ stabilizers. Polym. Eng. Sci. (2011). DOI 10.1002/pen.21893

33. C. M. Sai Prasanna1, S. Austin Suthanthiraraj. Investigations of zinc ion dissociation in gel polymer electrolytes

34. based on poly, (vinyl chloride) and poly(ethyl methacrylate) blend on the addition of two different ceramic nanofillers. Journal of Inorganic and Organometallic Polymers and Materials. 29, 483 (2019)

35. H.H. Redhwi, M.N. Siddiqui, A.L. Andrady, Y. Muhammad, H.Syed. Weatherability of conventional composites and nanocomposites of PVC and rutile titanium dioxide. Polym Composites (2018). DOI $10.1002 /$ pc. 24176

36. V. Mathur, P.K. Arya, Dynamic mechanical analysis of $\mathrm{PVC} / \mathrm{TiO}_{2}$ nanocomposites. Advanced Composites and Hybrid Materials 1, 741 (2018)

37. V. Najafi, E. Ahmadi, F. Ziaee, H. Omidian, H. Sedaghat. Polyaniline-modified $\mathrm{TiO}_{2}$, a highly effective photo-catalyst for solid-phase photocatalytic degradation of PVC. Journal of Polymers and the Environment. 27, 784 (2019)

38. E.M. Sadek1, N.A. Mansour 1, S.M. Ahmed1, S. L. Abd-El-Messieh, D. El-Komy1, Synthesis, characterization and applications of poly(vinylchloride) nanocomposites loaded with metal oxide nanoparticles. Polym. Bull. (2020). https://doi.org/10.1007/s00289-020-03371-5

39. A. Olad, S. Behboudi, A.A. Entezami, Effect of polyaniline as a surface modifier of $\mathrm{TiO}_{2}$ nanoparticles on the properties of polyvinyl chloride/ $\mathrm{TiO}_{2}$ nanocomposites. Chin. J. Polym. Sci. 31, 481 (2013)

40. M. Hasani, A.N. Banerjee, M. Lee, Enhanced thermomechanical performance and strain-induced band gap reduction of TiO2@PVC nanocomposite films. Bull. Mater. Sci. 38, 283 (2015)

41. S.G. Mehmandoust, R. Alizadeh, A.A. Babaluo, Kinetic study of the poly (vinyl chloride)/

42. titanium dioxide nanocomposites, photo-degradation under accelerated ultraviolet and visible light exposure. Polym. Adv. Technol. 25, 799 (2014)

43. K. Liang, R.X. Li, G.Y. Liu, Study on evaluation methods for heat stability of PVC. Plastics Science and Technology 37, 29 (2009)

44. S. Krimm, Infrared spectra of high polymers (Springer, 1960)

45. S. Krimm, V.L. Folt, J.J. Shipman, A.R. Berens, Infrared spectra and assignments for poly (vinyl chloride) and deuterated analogs. J Polym Sci Part A: Gen Pap 1, 2621 (1963)

46. R.R. Stromberg, S. Straus, B.G. Achhammer, Infrared spectra of thermally degraded poly (vinyl chloride). J Res Nat Bur Stand. 60, 147 (1958)

47. J.B. Zhou, G. Ben, Q. Yu, J. Zhang, W.X. Wang, H. Yao, Y. Yu, M.H. Xu, Understanding the pyrolysis mechanism of polyvinylchloride (PVC) by characterizing the chars produced in a wire-mesh reactor. 
Fuel 166, 526 (2016)

48. P.Y. Jia, L.H. Hu, M. Zhang, Y.H. Zhou, TG-FTIR and TG-MS analysis applied to study the flame retardancy of PVC-castor oil-based chlorinated phosphate ester blends. J. Therm. Anal. Calorim. 124, 1331 (2016)

49. C.J. Wang, H.R. Liu, J.Q. Zhang, S.L. Yang, Z. Zhang, W.P. Zhao, Thermal degradation of flameretarded high-voltage cable sheath and insulation via TG-FTIR. J. Anal. Appl. Pyrol. 134, 167 (2018)

50. X.M. Feng, W.Y. Xing, L. Song, TiO2 loaded on graphene nanosheet as reinforcer and its effect on the thermal behaviors of poly (vinyl chloride) composites. Chem. Eng. J. 260, 524 (2015)

51. S. Mallakpour, M.Adnany Sadaty, Thiamine hydrochloride (vitamin B1) as modifier agent for TiO2 nanoparticles and the optical, mechanical, and thermal properties of poly (vinyl chloride) composite films. RSC Advances. 6, 92596 (2016)

52. C.H. Zheng, Z.M. Qi, W.C. Shen, G.Q. Chen, Self-cleaning Bom-byx mori silk: room-temperature preparation of anatase nano-TiO2 by the sol-gel method and its application. Color Techno. 130, 280 (2014)

\section{Figures}




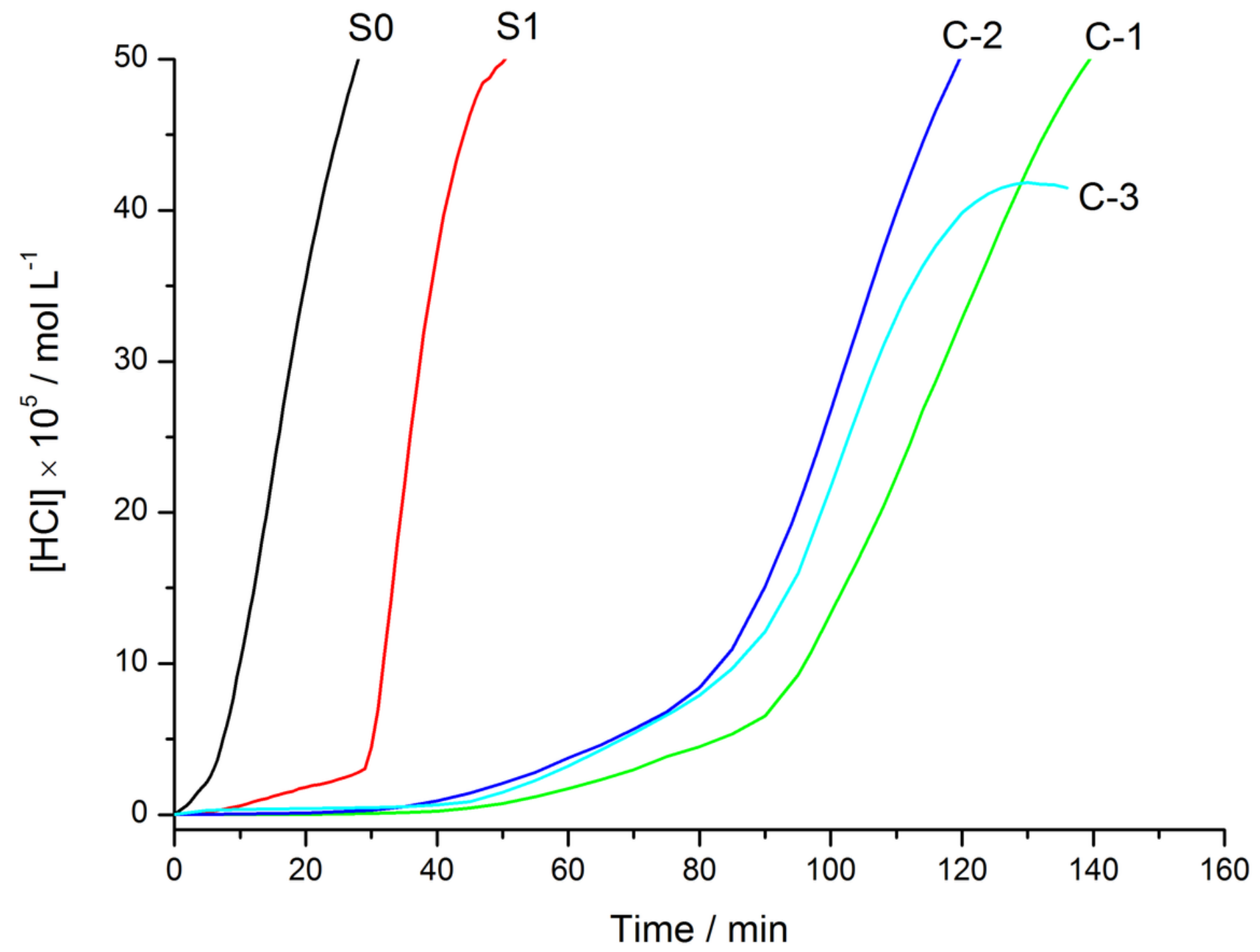

Figure 1

The change curves of the concentration of the aqueous hydrogen chloride solution released by different PVC films over time (at $195^{\circ} \mathrm{C}$ and under an N2 atmosphere) 


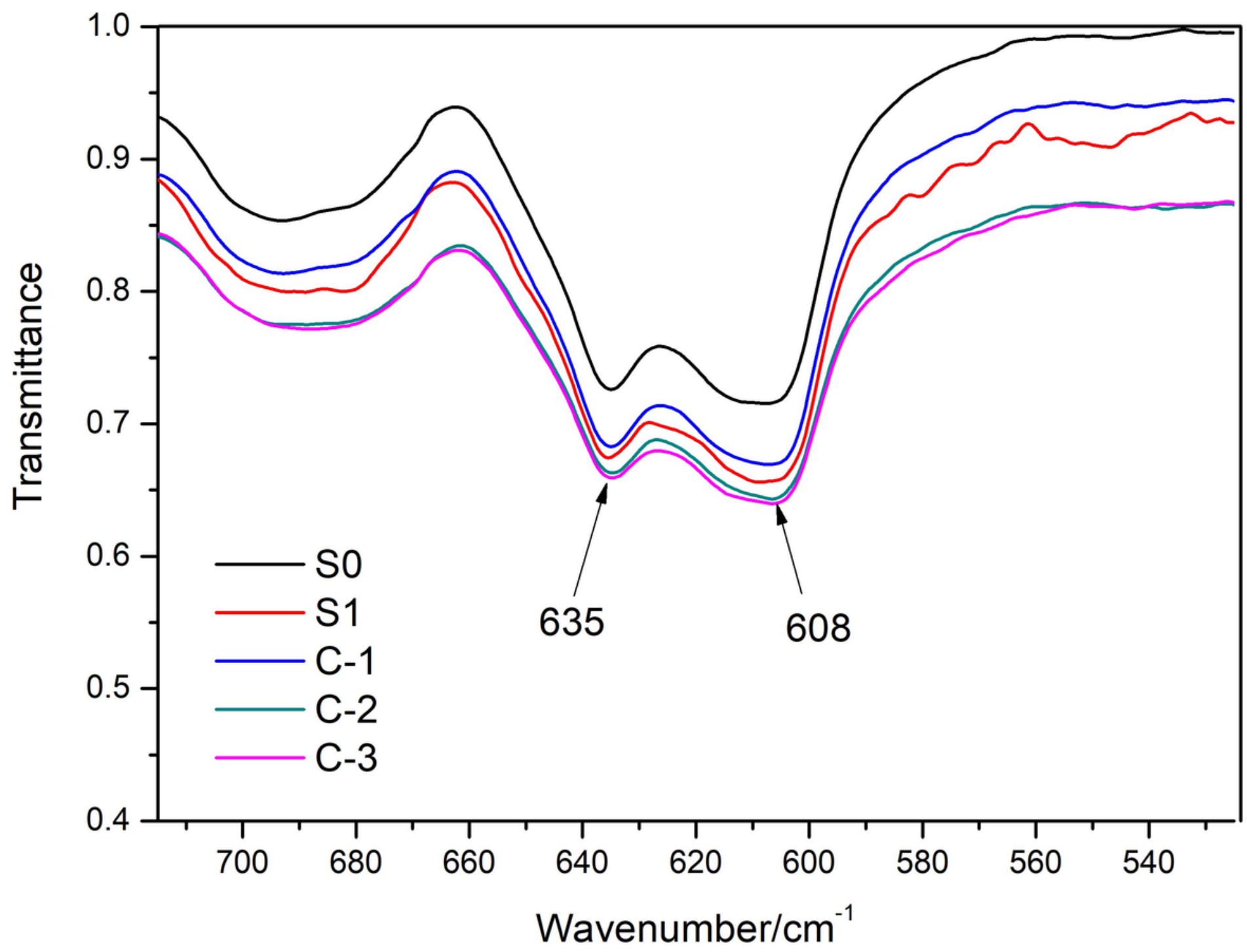

Figure 2

FT-IR reflectance spectra of the different PVC films 


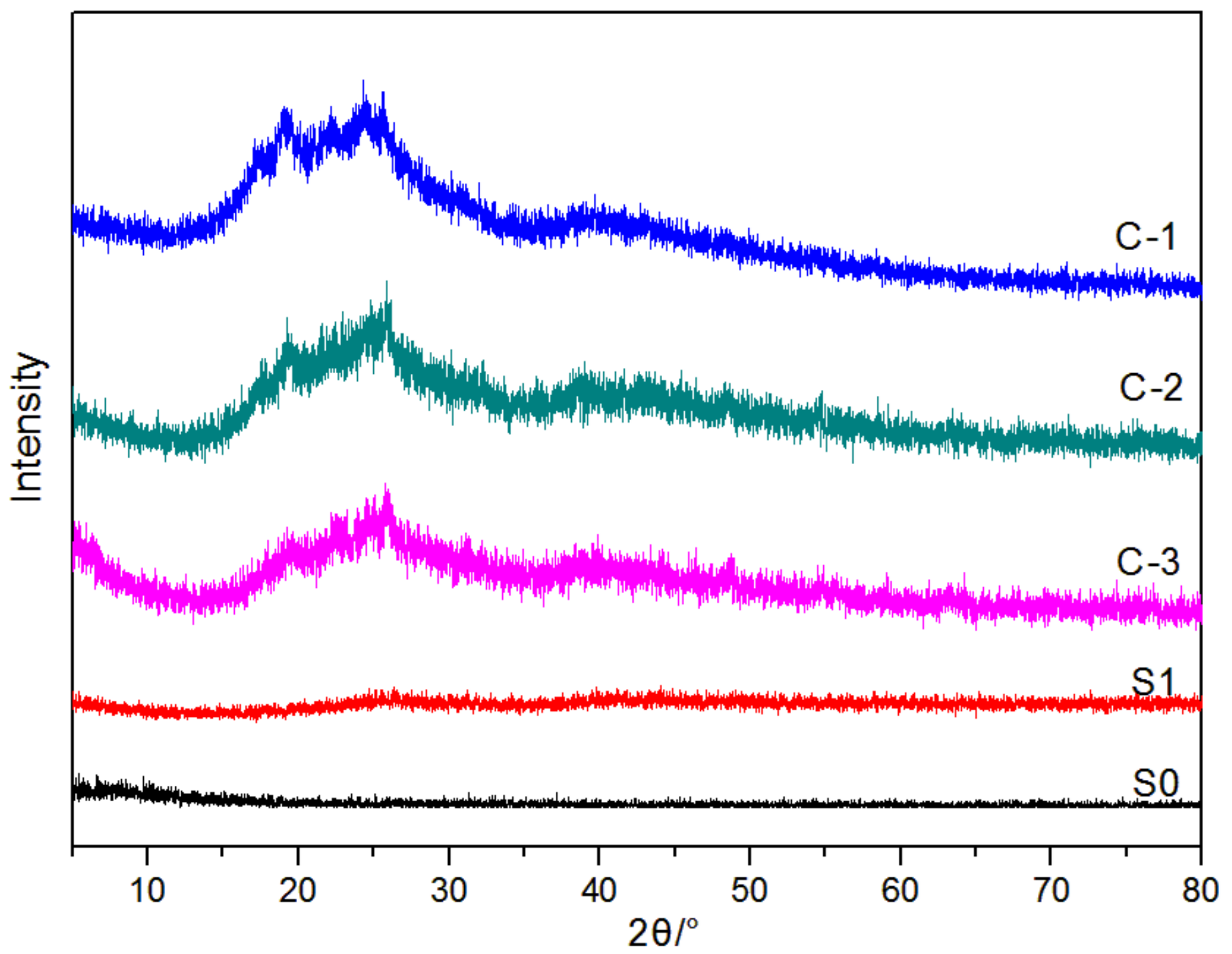

Figure 3

XRD profile of different PVC films
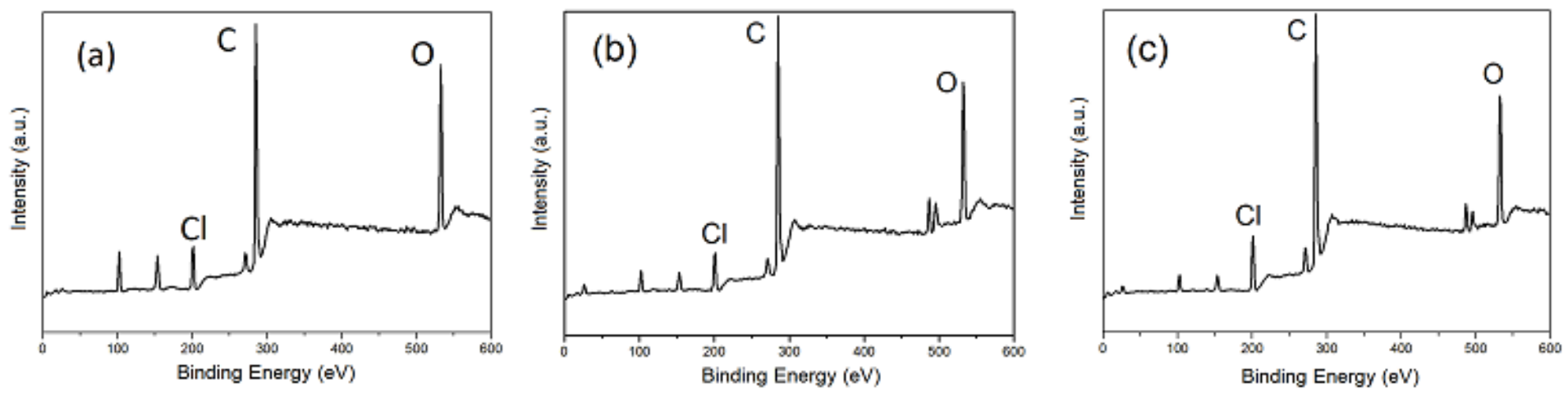

Figure 4

XPS spectra of PVC films (a) C-1, (b) C-2 and (c) C-3 

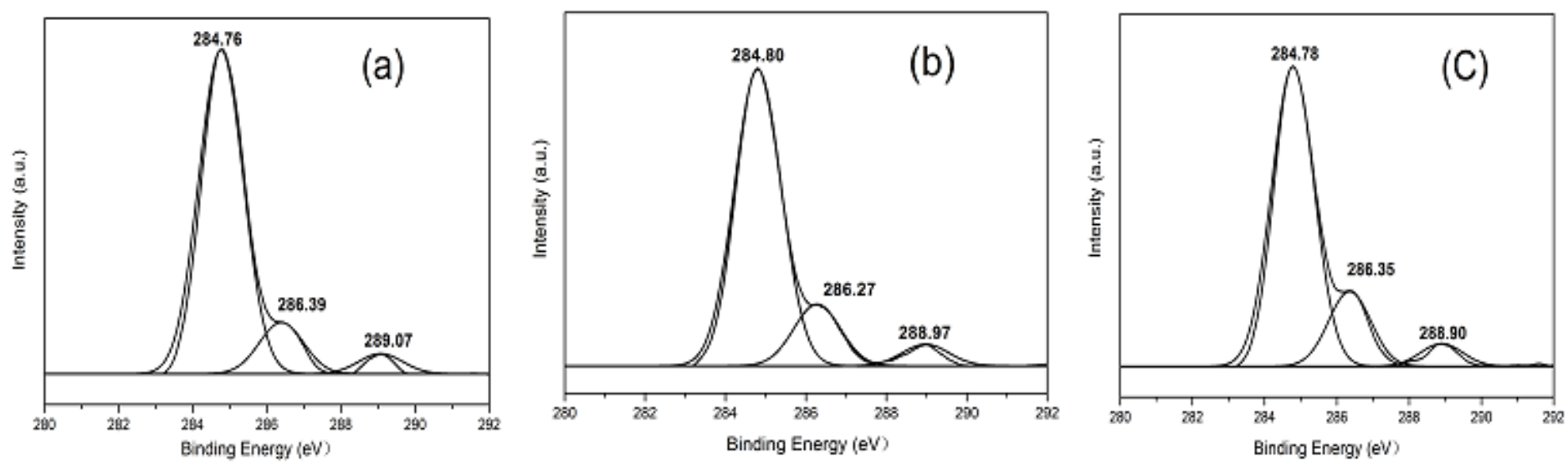

Figure 5

XPS spectra of high-resolution scans of the C 1s region of (a) C-1, (b) C-2 and (c) C-3
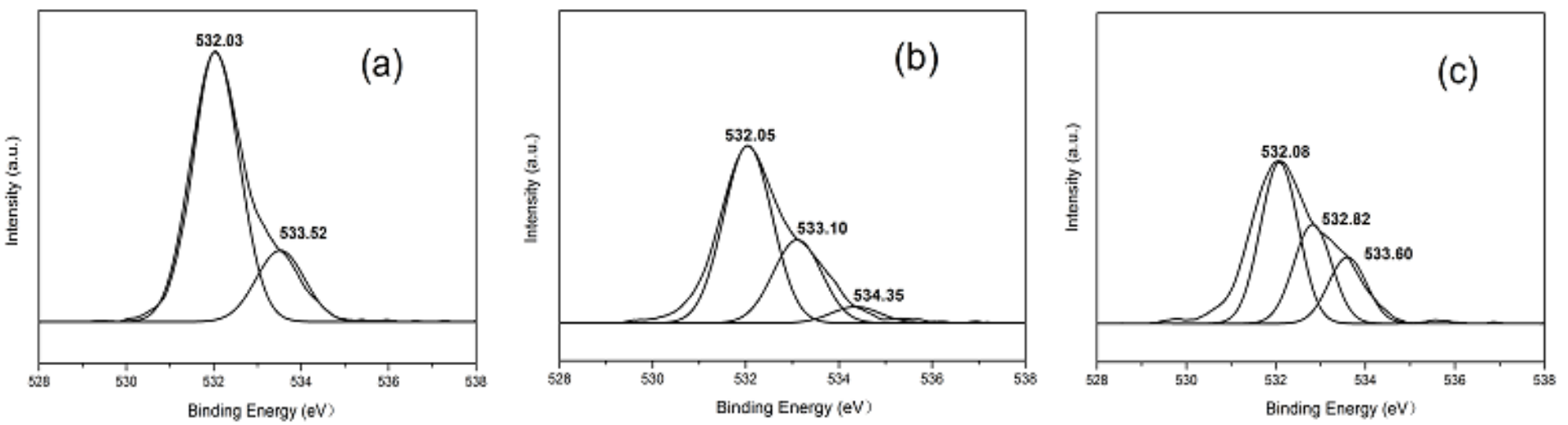

Figure 6

XPS spectra of high-resolution scans of the 0 1s region of (a) C-1, (b) C-2 and (c) C-3
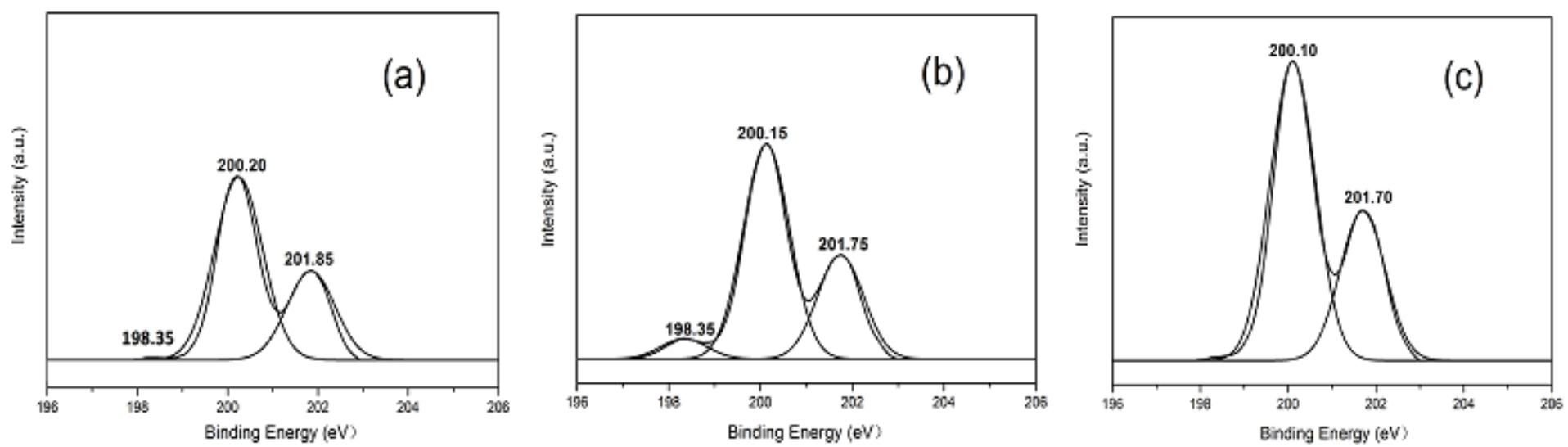

Figure 7

XPS spectra of high-resolution scans of the $\mathrm{Cl} 2 \mathrm{p}$ region of (a) C-1, (b) C-2 and (c) C-3 

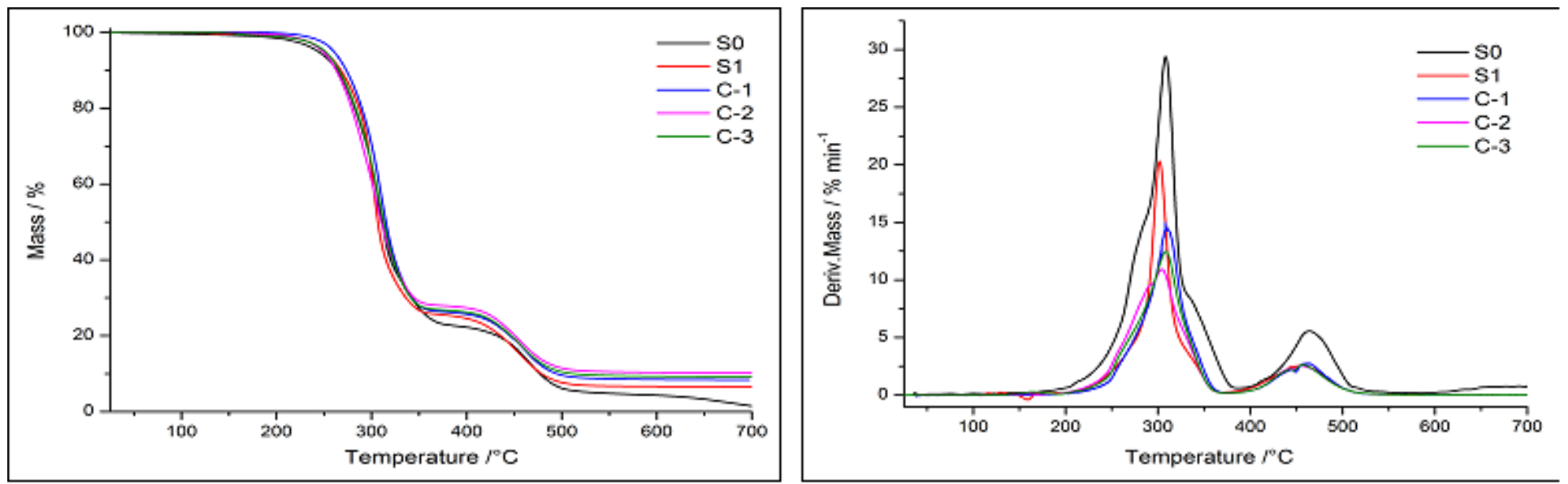

Figure 8

TG-DTG curves of different PVC films
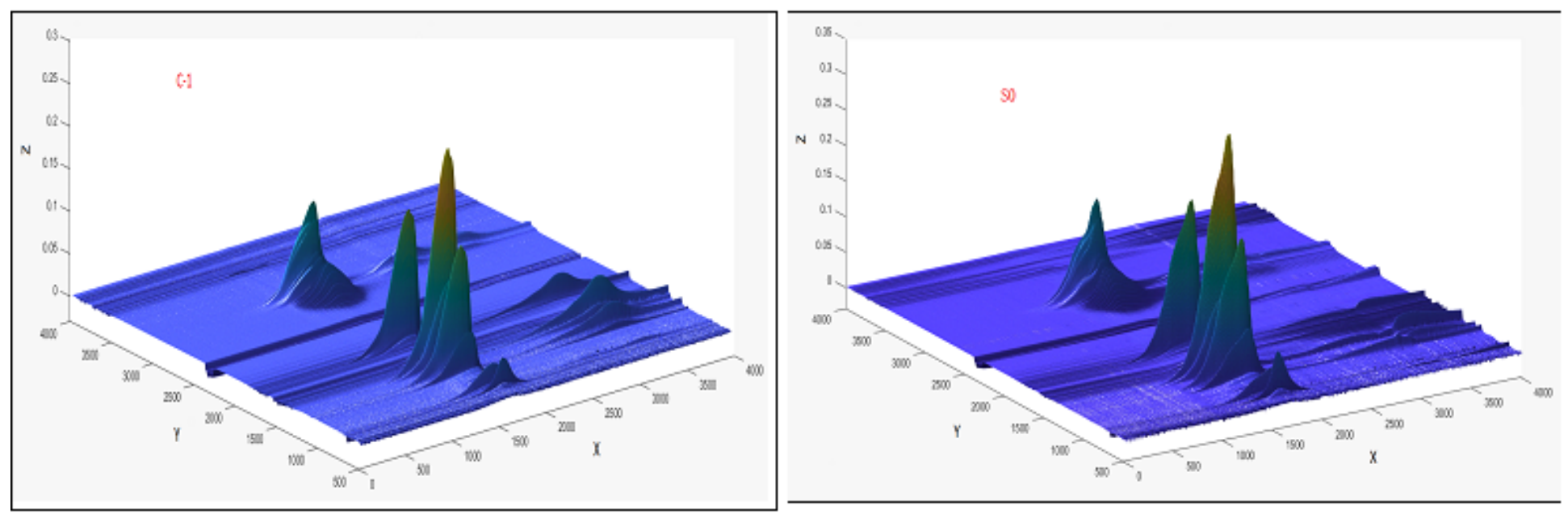

Figure 9

3D TG-FTIR spectrum of the gas phase in the thermal degradation of (a) C-1 and (b) S0 (time: 0-4000 s; temperature range: room temperature $-700^{\circ} \mathrm{C}$; wavenumber: $500-4000 \mathrm{~cm}-1, \beta=10^{\circ} \mathrm{C} / \mathrm{min}$, carrier gas: high purity nitrogen; X-time/s; Y-wavenumbers/cm-1; Z-Absorbance) 

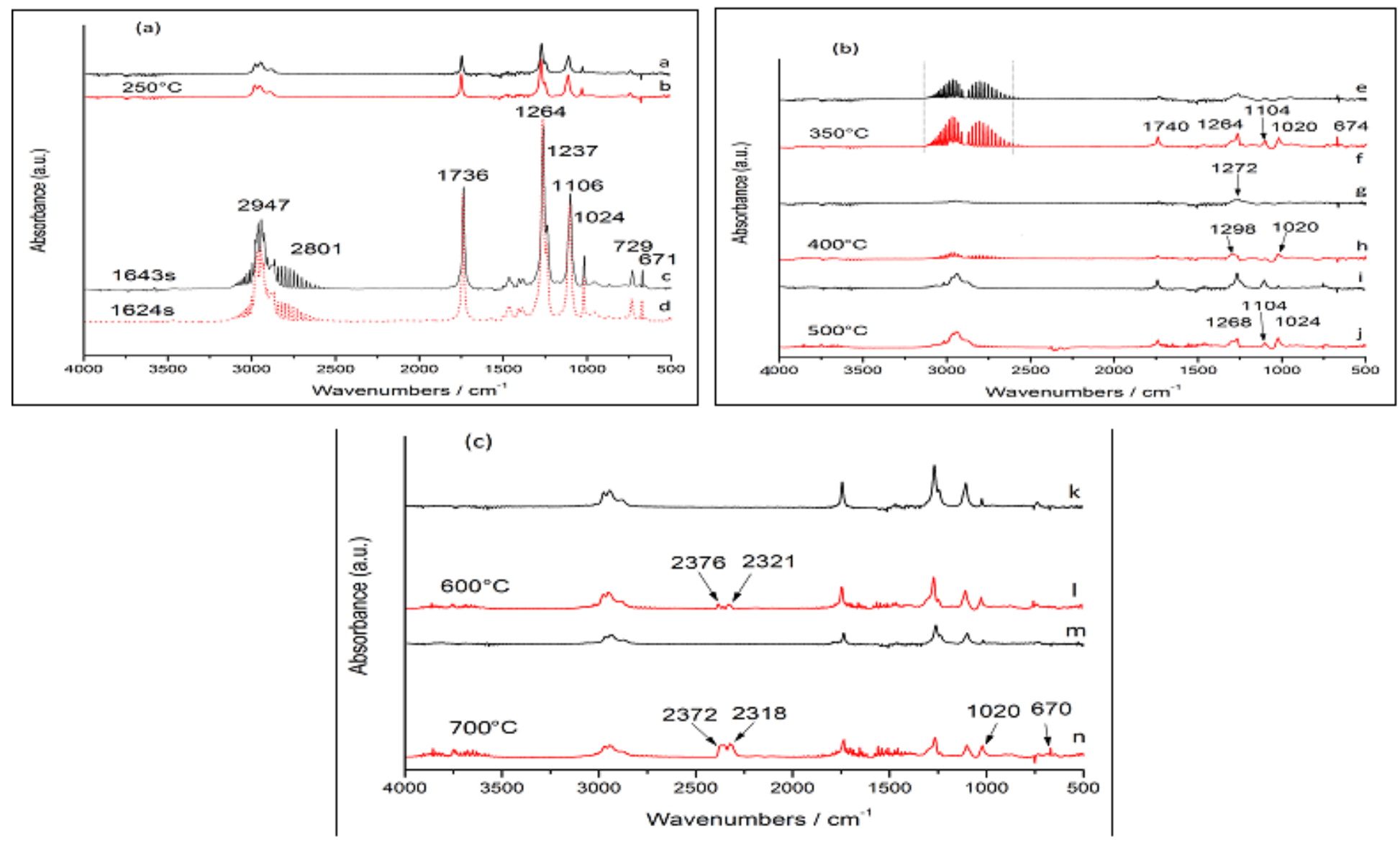

Figure 10

FTIR spectra of PVC at different temperatures (black is C-1; red is S0; a, b-250 ${ }^{\circ} \mathrm{C}$; c-1643s (time), d- $1624 \mathrm{~s}$ (time); e,f-350 ${ }^{\circ} \mathrm{C} ; \mathrm{g}, \mathrm{h}-400^{\circ} \mathrm{C} ; \mathrm{i}, \mathrm{j}-500^{\circ} \mathrm{C} ; \mathrm{k}, \mathrm{l}-600^{\circ} \mathrm{C} ; \mathrm{m}, \mathrm{n}-700^{\circ} \mathrm{C}$ )

\section{Supplementary Files}

This is a list of supplementary files associated with this preprint. Click to download.

- SupplementaryInformationSI.doc 